\title{
T-Cell Large Granular Lymphocyte Leukemia Expressing the T-Cell Receptor
} Gamma-Delta

National Cancer Institute

\section{Source}

National Cancer Institute. T-Cell Large Granular Lymphocyte Leukemia Expressing the TCell Receptor Gamma-Delta. NCI Thesaurus. Code C39586.

An uncommon variant of T-cell large granular lymphocyte leukemia expressing the gamma-delta T-cell receptor. Approximately $60 \%$ of these cases are CD8-positive and the remainder are CD4/CD8-negative. 